\title{
THE HEAVENLY HUNGER
}

He fights with his hat. It's a mouth attempting to swallow him.

The hat suffers, but that's all right, it has no nerve endings.

When the hat is entirely ruined he says, don't try that again.

Again he is ready to leave. He puts on another hat, but sees it is also a mouth trying to get funny with him. This hat gets a good knocking about, and like the first hat, is without nerve endings.

Oh, hell, who needs a hat?

But then he discovers that his shoes are two mouths trying to eat him feet-first; some kind of a two headed creature, a tuning fork which will consume and vibrate him to death with road rhythms and footfalls ...

Even the rooms of the house are discovered to be the several stomachs of a monster cow digesting him ...

How long does the final appetite of heaven hold its hunger...? 